\title{
Enhancing Resiliency of Perishable Product Supply Chains in the context of the COVID-19 Outbreak
}

\author{
Saket Shanker, Akhilesh Barve, Kamalakanta Muduli, Anil Kumar, Jose Arturo Garza- \\ Reyes, Sudhanshu Joshi
}

\begin{abstract}
Globally, countries are struggling to fulfil customer demands due to the effects of the COVID-19 pandemic on perishable food supply chains (PFSCs). This study aims to analyse the factors influencing PFSCs during the pandemic and improve their resiliency. This is essential as some factors discourage the productive execution of PFSCs and decrease organizational performance, thus lowering stakeholder satisfaction. This study has been conducted in two phases. The first phase, through extensive review and discussion with experts, identifies the influencing factors related to supply chain (SC) disturbances in PFSCs. In the second phase, a hybrid method i.e. g-DANP, a combination of grey-decision making trial and evaluation laboratory and analytic network process, is employed to develop a hierarchical structure to measure their influence. The proposed framework is validated with a case of the current COVID19 outbreak. The study revealed that factors, restriction on import-export and fear of violation of social distancing guidelines, are the primary "cause" group factors; whereas, price variation of perishable products and panic buying and stockpiling are the crucial "effect" group factors affecting the PFSCs. The findings also enrich existing literature by providing analytical support to relationships between various factors affecting PFSCs during the pandemic. The results of this study can be utilised by decision-makers to anticipate the operative and long-haul effects of COVID-19 on PFSCs and create plans to deal with the pandemic.
\end{abstract}

Keywords: Operational Excellence; Pandemic; COVID-19; Perishable Food Supply Chain; Grey-DEMATEL, ANP

\section{Introduction}

Supply chain disruption is the root cause of failure of a business strategy, companies and transportation services. (Dmitry Ivanov, 2020). SC disruptions are multifarious and can be categorized under the headings of general and specific disruptions (Dmitry Ivanov, 2020; Xu et al., 2020). General disruptions in a SC may be caused by communication failure, excessive inventory, volatile demand etc.; specific disruptions are due to the occurrence of cataclysmic 
events (e.g. 2001 Gujarat earthquake, 2013 North India floods etc.), pandemics (e.g. Yellow Fever Epidemic of 1793, Spanish flu of 1918-20, 2002-04 SARS outbreak, 2009 swine flu pandemic and the recent COVID-19) etc.; these have a low frequency of occurrence yet cause high impact disturbances (Ivanov et al., 2017; Kinra et al., 2019).

The recent coronavirus outbreak has disturbed all sorts of activities (Dmitry Ivanov, 2020; Fortune, 2020), creating extraordinary circumstances for people to live in (Tropics, 2020). To handle the outbreak, governments all over the world, including India, have adopted lockdown and shut down measures. India announced a three-week lockdown across the country till midApril 2020 in the initial stage; this was continued till May 30 to try to contain the corona spread (Affairs, 2020). During these challenging times, the demand for essential items (e.g. medicinal products, dairy products, vegetables etc.) (Ministry of Consumer Affairs, 2020) has increased, but due to the pandemic, various activities related to SCs have stopped (Goldbeck et al., 2020). This has resulted in disruptions to SCs for essential items such as pharmaceuticals (Hasani et al., 2015)), perishable foodstuffs (Rosales Fabricio et al., 2019)), etc.

The need for medicine and food, the most basic amenities for survival during these challenging times, must be acknowledged and appropriately analysed. Many recent studies have already been conducted on the impact of this outbreak on the pharmaceutical sector (Brown and Goodwin, 2020). But surprisingly, very few works have focused on the food sector (Béné, 2020; Singh et al., 2020); originating primarily from the perishable food supply chain, this area remains largely unstudied and unexplored. PFSC is currently one of the most affected supply chain categories due to the pandemic. Henceforth, this study fills the gap on disruptions to PFSCs caused by the pandemic by addressing the following questions:

- What are the factors influencing PFSC during the pandemic and how do they influence other factors?

- What is the significance of individual factors in a consolidated decision framework? Therefore, the objectives of this study are

- To recognize factors influencing PFSC during the pandemic and develop an interrelationship framework

- To quantify the cause-and-effect influence of each factor in a combined relationship with factor dimensions and their sub-factors 
- To compute the priority weight of the factors and propose managerial implications to improve PFSCs during pandemics

It is helpful to analyse the relationship between multiple criteria influencing PFSCs and propose a model to reference them (Tran et al., 2020). Our model development process begins with the literature survey, as shown in Figure III, and selects the most influencing factors. Data on factors and their sub-factors is collected from a range of scientific literature and reports; specialists' opinions are also considered. After determining main factors, specialists are furnished with a framework dependent on literature-based factors and are welcomed to propose any other significant factors. For instance, academic experts suggested, "Nation-Wide Lockdown (G3)" as a substantial factor influencing PFSC during the pandemic; specialists from F.C.I. (Food Corporation of India) and associated experts agreed. Finally, the factor's dimensions are categorized under four principle dimensions: operational; technological and infrastructural; government policy and regulation plus behavioural. This study has further developed a structure with reconciliation of grey theory-based decision-making trial and evaluation laboratory (greyDEMATEL) and analytic network process i.e. g-DANP strategy for computing factor interrelationships and priority weights. Past research works have integrated two or three techniques (Supeekit et al., 2016; Govindan et al., 2018), although a few recent investigations have consolidated grey theory-based DEMATEL and ANP techniques for analysis of inter-connection of factors and importance of weight calculations.

The entire work is divided into 8 sections. In Section 2, the literature on PFSC is provided. Section 3 discusses factors influencing PFSC during the pandemic. Section 4 gives an example of a case illustration. Section 5 presents results and discussions; implications for practice and further research are suggested in Section 6. Section 8 delivers concluding remarks.

\section{Literature Review}

\subsection{Perishable Food Supply Chain}

There has been a spate of academic intrigue and publications in the area of PFSC. Therefore, this segment features the main studies that have strived to recognise the various developments and issues associated with PFSCs. Employment of a radio-frequency identification (RFID) technique 
was proposed by Grunow and Piramuthu (2013) to help decrease wastage in PFSC. Willem et al. (2014) surveyed whether an existing sourcing methodology can successfully supply products of suitable quality with acceptable levels of product waste when applied to a global PFSC. Aggarwal and Srivastava (2016) presented the processes and roles of SC collaboration in the Indian agri-food industry, describing the impression of purchasers and providers towards one another. Prakash et al. (2017) analysed the risks present in PFSCs and determined essential risk mitigation strategies. Mor Rahul et al. (2018) explored the critical performance indicators that served as a decision support in dairy SC practices by examining their communications with regards to the Indian dairy sector. Kumar et al. (2020) used an integrated decision framework to formulate the critical challenges to sustainability in a PFSC.

Some studies have focused on the recent COVID-19 pandemic and the food sector. For example, Singh et al. (2020) discussed the impact of COVID-19 on logistics systems and disruptions in the food SC and described the importance of a resilient SC during a pandemic. The study developed a simulation of a public distribution system network to demonstrate disruptions in the food SC. Their findings have scope for developing a robust food SC. Reardon et al. (2020) answered the question, "How will COVID-19 affect food supply chains in developing countries?" The study discovered that the greatest problems will be faced by small and medium-sized enterprises in urban areas, rather than operators. It suggests that governments will need to develop new policies to avoid supply chain disruptions. As opposed to the above-mentioned literature, this study aims to analyse the factors influencing PFSCs during the COVID-19 pandemic. The framework used in this paper gives a priority ranking for the barriers identified to help policymakers to mitigate the effects of the pandemic on PFSCs.

\subsection{COVID-19 Scenario in the Food SC - Pandemic and Indian PFSCs}

The perishable food sector has been the main impetus in invigorating a healthy development pattern in Indian agriculture (Birthal et al., 2020; Vaid, 2020), poultry (Dhanaselvi and Gayathri, 2019), dairy (Kumar, 2020), and fisheries (Prakash et al., 2020). Figure I shows a detailed description of the perishable food sector. This sector is perhaps the most crucial in the food supply chain (Tropics, 2020) and economic development of the nation (Halder and Pati, 2011). According to the FICCI report of 2019, India is the world's second-largest producer of fruits and vegetables (311.7 million tons). India enjoys a similar stature in the production of marine items (12.60 million metric tons), meat (7.7 MT of meat produced annually) and poultry (around 95.2 
billion eggs annually). India is the largest producer of milk in the world, with production estimated at 176.35 MT (Division, 2019). This shows that India is among the pre-eminent nations in the production of perishable goods. This sector accounted for $23 \%$ of GDP, employing $59 \%$ of the total workforce before the pandemic ( $\mathrm{Dev}$ and Sengupt, 2020). India's growth in GDP was $4.2 \%$ in the pre-COVID-19 period with the perishable sector GDP showing an annual average development rate of $3.2 \%$ in the six-year time frame of 2014-15 to 2019-20, with sporadic fluctuations (Fund, 2020).

\section{[Insert Figure I]}

After the COVID-19 outbreak, PFSCs were hit hard (Dev and Sengupt, 2020; Fernandes, 2020); vast amounts of food were wasted, leading to massive losses for Indian farmers (Bhosale and Sally, 2020; Bhosale, 2020). Media reports show that the closure of inns, cafés, sweet shops and coffee bars during lockdown is affecting milk sales (Khanna and Pande, 2020). The mass migration of workers has also lessened demand for milk in urban regions (Dev and Sengupt, 2020). These elements impact on milk producers unfavourably. Due to lack of demand, dairy ranchers are dumping milk into drains. Unable to export their produce, numerous farmers are also dumping seasonal products e.g. grapes, pomegranates etc (Kamal, 2020). Figure II gives a detailed description of the food products exported from different states of India (Thornton, 2017) and the percentage of COVID-19 cases reported from those states (MoHFW, 2020); the result is a disruption of food supply chains in India. Poultry farmers have been badly hit because of misinformation; primarily web-based networking media have reported that chickens are transporters of COVID-19. Many small poultry farmers across the nation, especially in the states of Maharashtra, Karnataka, Orissa and Andhra Pradesh, are battling to survive after sales crashed by $80 \%$ over these false claims (Reddy, 2020; Raj, 2020). This shows that despite being considered an essential service, PFSCs have been badly hit.

[Insert Figure II]

\section{Factors Influencing PFSC During the Pandemic}

A detailed discussion about factors and their sub-factors is presented in this section.

\subsection{Operational Factors (O)}


Operational factors are factors that affect perishable food supply chain performance (LimaJunior and Carpinetti, 2020; Swierczek and Szozda, 2019). This includes various operations that are essential for PFSCs to run smoothly. Researchers have noted that the working of a PFSC is considered smooth when 1) Production units using perishable products work efficiently (Dolgui et al., 2020); 2) Transportation services deliver perishable products to the next level of chain at the right cost and in good quality ( demand and maintain a proper flow of money (Badakhshan et al., 2020). But due to COVID-19, these operations have been interrupted, resulting in disruption of PFSCs (Dmitry Ivanov, 2020; Tropics, 2020). This section gives a detailed description of the operational factors affecting PFSCs during the pandemic.

\subsubsection{Production Shutdown (O1)}

The Food Service Industry (FSI) is the main production unit using perishable products as feedstock (Leena Jaisani et al., 2017). The Indian FSI is categorized under organized and unorganized sectors, comprising of cafes, dhabas, small roadside eateries chains etc.; these use about $40-60 \%$ of perishable goods produced in India (Thornton, 2017). India also has a large and rapidly growing business sector for milk and dairy items (Division, 2019), mainly taken up by the food service industries. This entire market has seen major disruption due to the virus, resulting in a complete shutdown of 500,000-plus restaurants across the country, as stated by the National Restaurant Association of India (NRAI) (Kumar and Grover, 2020).

\subsubsection{Price Variation of Perishable Products (O2)}

According to the Agricultural Produce Market Committee (APMC), demand for perishable goods has declined as bulk orders (from restaurants, cafes etc.) have stopped (Bhosale and Sally, 2020). This has resulted in a fall in prices for perishable commodities such as vegetables, grapes etc. by $15-20 \%$ (Bhosale, 2020) whereas for milk, it is $25-50 \%$ (Dev and Sengupt, 2020). The poultry, meat and seafood industries have been badly hit with a decrease in prices of about $85 \%$ (Dev and Sengupt, 2020). Variations in price have caused PFSCs to face unprecedented and severe losses, directly affecting functioning and performance.

\subsubsection{Cash Flow Constraints (O3)}

Cash flow or liquidity can be defined as the synchronization between inflows and outlays of money in a SC (Lyngstadaas, 2019). Any disturbance in cash flow or liquidity can cause disruptions in the functioning of processes of that particular SC (Badakhshan et al., 2020). The 
recent pandemic has caused constraints in cash flows for PFSCs. Cash outflows (in processing, feed, marketing etc.) in PFSCs during the pandemic are more significant than cash inflows (government payment etc.), and the stock of cash held, along with any money raised by selling products (Dev and Sengupt, 2020). This factor will affect future operations and performance of PFSCs.

\subsubsection{Inadequate Capability to Fulfil Customers' Orders (O4)}

Covid-19 has seriously impacted on manufacturers' capability to produce goods and meet customer orders on a timely basis, thus hindering the performance of many SCs for essential items e.g. pharmaceuticals, perishable goods etc. (Fiorini et al., 2020). Many perishable product companies have implemented "Just-in-time" or "Lean management" strategies, to mitigate the

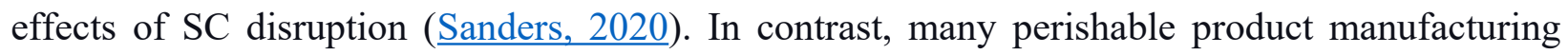
facilities have closed or reduced their operations (Joyce Mazero and MacPhee, 2020). Also, ports have closed, containers have reduced shipments, while other modes of transportation sit on "deferred status" (Sanders, 2020). All these factors have severely impacted cross-border distribution of perishable products.

\subsubsection{Poor Delivery Reliability (O5)}

Managing SC flexibility to ensure efficient product flow and on-time delivery remains a significant challenge for PFSCs during the pandemic (Joyce Mazero and MacPhee, 2020). Online platforms are working hard to deliver essentials such as fruits, vegetables, milk etc. (Peermohamed, 2020). Still, a lack of delivery slots has created uncertainty in PFSCs. E-retailers are witnessing increased demand from consumers (three to five times more than normal) following the ongoing nation-wide lockdown (Thind, 2020; Peermohamed, 2020). Many Eretailers have seen 1.2 - 1.3 million daily active users on their platforms despite no delivery slots (Peermohamed, 2020; Thind, 2020); this has created uncertainty and unreliable delivery agents for PFSCs.

\subsubsection{Increased Overall Transportation Cost (O6)}

Transportation plays an essential role in SCs (Albertzeth et al., 2020); this role is particularly critical in transporting perishable food like fruits and vegetables because of the short-time span of usability, high transitory, required controlled temperature etc. (Shukla and Jharkharia, 2013). Transportation is a crucial element of PFSCs (Rossi et al., 2020). But with the arrival of COVID19, transportation systems have disturbed PFSCs in the most brutal way possible (Gray, 2020), 
as truckers and transporters have increased prices by $80 \%$ (Chowdhury, 2020). Freight operators are adding surcharges (such as $25 \%$ emergency situation surcharge (ESS) ) for transportation as they grapple with significant shortages of human resources (from truck drivers to on-field delivery workers) for logistics (Chowdhury, 2020). Hence, given the depreciation in prices for perishable products and increased overall transportation costs, pressures on PFSCs have resulted in a major drop in performance.

\subsection{Behavioural Factors (B)}

Behavioural factors can be defined as factors stemming from human behaviour (Fischlmayr, 2009). Behavioural factors are among the most influencing factors affecting PFSCs during the pandemic as the virus has created an environment of heightened anxiety, fear and uncertainty about the future (Wang et al., 2020). This section provides a detailed subjective analysis of behavioural factors affecting PFSCs arising from this environment.

\subsubsection{Panic Buying and Stockpiling (B1)}

COVID-19 has influenced virtually every aspect of the economy, including customer behaviour

(Wang et al., 2020). In the midst of an emergency, purchases of products are guided by very different reasoning than in normal times (Notebaert, 2020). The global pandemic has triggered stockpiling behaviour (Sim et al., 2020). This stockpiling behaviour is called 'panic buying'; it is neither helpful nor sensible. Stockpiling has created a significant shortage of essential items (such as long-life vegetables, dairy products, medicines etc.) in supermarkets, pharmacies and other stores. Hence, stockpiling is creating a bottleneck in SCs for essential items. PFSCs and SCs for pharmaceuticals have been affected.

\subsubsection{Consumer Sentiments (B2)}

COVID-19 has severely impacted the domestic poultry industry (Ghosal, 2020). Rumours circulated in social media have affected consumer opinion regarding poultry products (Dyal, 2020; Dev and Sengupt, 2020). Whereas, few entities are witnessing / likely to witness the closure of the business (Ghosal, 2020).

\subsubsection{Fear of Violation of Social Distancing Guidelines (B3)}

Social distancing is an effort to stop transmission of coronavirus in large crowds in supermarkets, mandis, malls etc. (Tilotia, 2020). Places where large crowds gather are either closed or have limited access, emphasising the significance of social distancing (Dev and 
Sengupt, 2020). Advice by the WHO encourages individuals working in these areas to reduce interaction with others (WHO, 2020). Despite these guidelines, the ground situation in numerous places is unsatisfactory as individuals constantly breach rules on social distancing norms (Wasdani and Prasad, 2020). Frequent violations of social distancing norms have created a psychological impact on many people working in sectors involving essential items; vendors and wholesalers are especially at risk as mandis (vegetable markets) in India are densely crowd (Roy et al., 2020). This psychological factor has resulted in fewer people working in the market (Dev and Sengupt, 2020), consequently affecting its functioning.

\subsubsection{Proactive Health-Minded Buying (B4)}

Before the pandemic most customers would go to a supermarket with a particular objective. But with the advent of COVID-19 and under time constraints, the majority of consumers do not have the opportunity to process product information, depending more heavily on heuristics; for example, brand name, value, product images and colour-coded labels govern their food choices, especially for perishable products (Martin-Neuninger and Ruby, 2020). This type of buying is known as proactive health-minded buying; this shows that people prefer global-PFSCs instead of local-PFSCs amidst the pandemic. This type of psychological behaviour is severely affecting PFSCs as local markets experience a decrease in their sales.

\subsubsection{Less Physical Buying (B5)}

In terms of behavioural changes, the rise in online buying, specifically for perishable products, is notable (News, 2020). Among all age groups, there is a large portion of buyers who tried online purchasing for the first time in March 2020; many will probably keep purchasing perishable products online, at least as long as the pandemic continues (News, 2020). Most people have forgotten the social experience of shopping, as they are maintaining a distance from physical buying (Martin-Neuninger and Ruby, 2020). Thus, the convenience of online channels has disrupted local PFSCs.

\subsection{Government Policy and Regulations (G)}

Governments have established many regulations and policies that guide PFSCs during the pandemic (Affairs, 2020). Some rules, like nation-wide lockdown, are mandatory to stop the virus from spreading, while other policies may influence PFSCs indirectly (Dmitry Ivanov, 2020). This flexibility should be not only at national level but also at local level, as states and 
districts have their own sets of rules (Williams, 2019). Indeed, there are also international rules that can influence PFSCs.

This section gives a detailed description of government regulations and policies affecting PFSCs during the pandemic.

\subsubsection{Closure or Limited Operation of Mandis (G1)}

Traders and agents in agricultural markets across the country are facing losses because of the closure or limited operation of mandis (Dev and Sengupt, 2020; Gray, 2020). Due to the spread of COVID-19 in fruit and vegetable wholesale markets, the government of India has either closed or enforced only limited operation of these markets. Such guidelines have led to a $60-80 \%$ decrease in the purchase of fruits and vegetables by retailers (Bhosale and Sally, 2020). As a result, retail prices of perishable products have increased, whereas wholesale rates have fallen by 25\% (Bhosale and Sally, 2020; Bhosale, 2020).

\subsubsection{Restriction on Import-Export (G2)}

With the global health crisis accelerating, most nations have shut their borders, limiting passenger and cargo movement (Dmitry Ivanov, 2020). In the midst of a total lockdown, manufacturing and other industries stay shut, affecting trade and the economy (Dev and Sengupt, 2020). This has dramatically influenced global exchange, especially PFSCs that rely upon import and export of perishable products like fruits, vegetables and certain processed foods (as shown in Figure II) (Thornton, 2017). Hence, significant losses have resulted for Indian farmers because of a non-existent international supply chain (Fortune, 2020).

\subsubsection{Nation-Wide Lockdown (G3)}

Nation-wide lockdown is the primary cause of disruptions in the PFSC (Bhosale, 2020; Bhosale and Sally, 2020). The lockdown has transformed the market through stringent rules and guidelines. The functioning of the entire PFSC is upset as newly imposed restrictions have adversely impacted the main drivers of SCs to a large extent (Dev and Sengupt, 2020; Dmitry

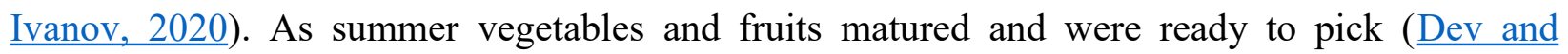
Sengupt, 2020; Sanders, 2020), the ranchers' hard work went to waste because of the unexpected halt to the market. Temporary bottlenecks and testing in warehousing facilities have become commonplace.

\subsubsection{Lack of Policies for Poultry, Marine Products and Dairy Farmers (G4)}


The pandemic has caused disturbances in livestock and poultry value chains in India, prompting a fall in acquisition and sale of animal-sourced food (Chandran, 2020; Dev and Sengupt, 2020; Dyal, 2020; Sanders, 2020). Animals are at risk because of insufficient feed and lack of veterinary support (Ghosal, 2020). Ranchers' problems are further aggravated by rumours and fake news connecting animal issues and COVID-19. All these are unfavourably influencing ranchers' income and the economy at the state/national level. Livestock extension and advisory services (EAS) are expected to support farmers to overcome these problems during this challenging period (Ghosal, 2020). The government must implement effective policies for poultry, marine products and dairy farmers.

\subsubsection{Sealing of State Borders due to Lockdown (G5)}

To contain the mass spread of COVID-19, several states have sealed their borders (Gray, 2020), impacting supplies of perishable goods as available inventory dwindled and fresh stocks were hard to come by (Dev and Sengupt, 2020). As a result, many areas in India were affected by price hikes or shortages of perishable products (Bhosale, 2020), consequently leading to disruption of PFSCs.

\subsubsection{Scarcity of Workforce (G6)}

The PFSC in India has been disrupted immensely due to shortage of labour. With the advent of COVID-19, workers have migrated to their homes, resulting in a shortfall of $80 \%$ of workers for the perishable goods sector (Gray, 2020). The government has issued notice for industries to keep working with $30-40 \%$ of their workforce (Peermohamed, 2020). With so few workers, companies are unable to cope with the demands for perishable products, consequently affecting PFSC performance.

\subsection{Technological and Infrastructural Factors (T)}

Technology and supply chain infrastructure plays an essential role in the perishable food sector. Appropriate and satisfactory infrastructure helps ranchers and agri-businessman to maintain their operations effectively and proficiently (Sinha and Anand, 2020). Technology can assist with tackling decreasing post-harvest income and time lost in operational exercises (Dagne et al., 2020).

\subsubsection{Poor Transportation Network (T1)}

Poor transportation networks are one of the most influential factors affecting PFSCs in time of crisis (Tropics, 2020). In India, despite a large number of ongoing infrastructure projects, there is 
a serious absence of labour with the appropriate abilities and training to handle modern transportation technology ( Shukla and Jharkharia, 2013). After the outbreak, many disruptions have led to add-ons and delay in time-definite deliveries in PFSCs (Dev and Sengupt, 2020).

\subsubsection{Technical Difficulties in Delivering Perishable Products with Minimum Human Contact (T2)}

COVID-19 has created significant problems for delivery agents delivering perishable goods to customers (howdhury, 2020). In a 'touch-me-not' environment (Bora, 2020), supplying products with minimum human contact is not possible everywhere in India because of its dense population (Goel and Yadav, 2020). Lack of COVID-19 testing and improper screening of delivery agents have caused severe disruptions in PFSCs; cases of delivery agents being infected

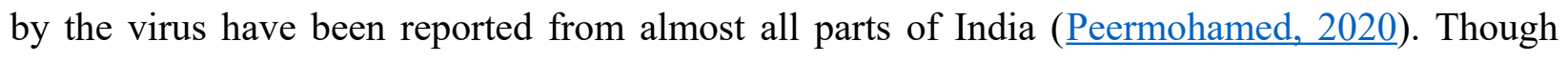
many companies have switched from personnel making deliveries to delivery drones (Bora, 2020), this technological advancement is not sufficient to overcome the disruption (Bora, 2020).

\subsubsection{Low Area Coverage of E-Commerce Platforms for Perishable Goods (T3)}

Reports suggest that the pace at which the Indian e-commerce sector is growing is awe-inspiring (Thind, 2020). But the recent pandemic has severely disturbed its operations and exposed gaping holes in farm supply e-commerce platforms (Thind, 2020). In India, before the arrival of COVID-19, the e-commerce platforms for perishable goods were limited to big cities (Peermohamed, 2020). After lockdown, people became highly dependent on e-commerce platforms; but online stores were unable to deliver perishable goods (vegetables, fruits, milk etc.) in many areas because they were not available (Peermohamed, 2020). Thus, low area coverage of e-commerce platforms for perishable products is a technological and infrastructural factor affecting PFSCs.

\subsubsection{Information Distortion (T4)}

One of the critical mechanisms for coordination in a supply chain is information flow among associates (Ramaswami et al., 2006; Shukla and Jharkharia, 2013). With the global pandemic, demand for perishable goods has increased in households leading to more orders at local retail

stores; this leads to supply pressures on wholesalers, hence creating a bullwhip effect in the PFSC (Dolgui et al., 2020). This bullwhip effect eventually reaches upstream manufacturers (i.e. the farmers) (Dolgui et al., 2020), hence distorting the information flow in the PFSC.

\subsubsection{Poor Packaging Capabilities (T5)}


Packaging is crucial for perishable products (Shukla and Jharkharia, 2013; Chen et al., 2020), especially during COVID-19. Without appropriate packaging, it is very difficult to avoid spreading the virus (Sim et al., 2020). In India, there is a culture of buying perishable goods from

local vendors without any sort of packaging. This culture has led India to focus less on its packaging capabilities (Thornton, 2017). The pandemic has caused a sudden increase in demand for packed items instead of un-packed ones (Tilotia, 2020), to avoid violations of guidelines issued by the government to stop the virus spread. The high demand for packed products is creating difficulties for farmers as they don't have facilities for proper packaging of their goods.

\section{Application of the Proposed Framework}

The case of the disruption caused to the Indian PFSC during the recent COVID-19 pandemic has been selected to apply and validate the proposed framework. The presented research framework (Figure III) has been used to analyse inter-relationships among factors and their sub-factors, and also to compute priority levels for decision making. The detailed process of data assortment and analysis are given in the accompanying sub-sections.

\section{[Insert Figure III]}

\subsection{Questionnaire Designing and Data Collection}

The factors affecting PFSC during the pandemic are identified from the literature review; confirmation of their applicability in the case study is made through the experts' inputs. In this study, specialists are selected from those who are multiple stakeholders; for example, academic researchers in the field of logistics and SC, perishable product companies and the Food Corporation of India (four specialists from each group). The factors considered and their subfactors are elucidated to every expert; all experts consented to give full responses. All experts chosen have relevant work experience of at least ten years. For inter-relationship analysis, a summed-up poll was circulated to all experts; this comprised a pairwise correlation scale ranging from "no influence" to "very high influence" as shown in Table 1. An appropriate number of experts improve the level of consensus in the decision-making procedure (Tseng, 2009).

\subsection{Determining Inter-relationships between Factors and Sub-Factors Affecting PFSC}


A plethora of MCDM techniques have been used in previous studies to evaluate multiple conflicting criteria. Methods such as the Technique for Order Preference by Similarity to Ideal Solution (TOPSIS), the Analytic Hierarchy Process (AHP) and the Elimination and Choice Translating Reality (ELECTRE) have been used to gauge the relation between factors (Supeekit et al., 2016). However, unlike the ANP methodology, these techniques fail to deal with interdependencies among elements. Furthermore, the inclusion of DEMATEL allows for the creation of causal diagrams to clearly visualize the causal relationships of sub-factors (Raj and Sah, 2019). DEMATEL is a useful technique to analyse cause-effect relationships and quantitatively present criteria in a related structural model (Tseng, 2009). However, the technique is unable to determine individual weights of the criteria. Thus, ANP is used to provide benefits in calculating criteria priorities and their relations (Abikova, 2020). In this regard, the proposed grey-DANP strategy is utilized to portray the decision-making problem. In literature, grey-DEMATEL is embraced in various fields of operational management (Xia et al., 2015; Raj and Sah, 2019). The proposed methodology (shown in Figure III) is more precise and significantly decreases the computational intricacy of the problem. It includes two stages (see Appendix A) to compute the inter-relationships and prioritization of factors influencing PFSCs during the pandemic.

As mentioned in Appendix A, the steps involved in grey-DEMATEL are applied as follows:

Step 1: Formulation of direct relationship matrix and crisp relationship matrix "A".

The experts' pairwise responses are collected based on the greyscale mentioned in Table 1. Thus, twelve individuals matrices are obtained. The procured matrices are then formulated based on Eq. 7 and the crisp relationship matrix is obtained.

Step 2: Normalised crisp relationship matrix "B".

The initial crisp relationship matrix is normalised with the help of Eqs. 9 and 10 and the normalised matrix is obtained.

Step 3: Calculation of total influence matrix " $\mathrm{T}$ ".

From the normalised matrix "B", the total influence matrix was computed using Eq. 11

Step 4: Formulate the sum of rows "“" and the sum of column "'”. 
The total influence transferred and received by each factor was calculated using Eq. 12. The total influence matrix of the dimensions is shown in Table 2.

\section{[Insert Table 2]}

Step 5: Plot cause and effect digraph

The cause and effect digraph is based on the influence received and given by the dimensions and sub-components; the influence map is developed, showing the relationships of one factor to another factor. The influential diagram of dimensions and sub-components are depicted in Figure IV.

\subsection{Weightings of the Dimensions and Criteria through g-DANP}

Continuing with the grey-DEMATEL technique, as shown in Figure III, the following steps are used to obtain the priority weight of factors.

Step 6: Computation of the unweighted super-matrix .

The unweighted super-matrix() can be obtained from the total influence matrix (T) by using Eqs. 14 and 17. After that, normalisation of the total influence matrix of dimensions is computed using Eqs. 19 and 20.

Step 7: Formulation of weighted super-matrix .

The weighted super-matrix (i.e., ) is formulated by using Eq. 21.

Step 8: Limit the weighted super-matrix.

The final weights of criteria are computed by limiting the power of the weighted super-matrix , where should have a higher value. The stable matrix of g-DANP is calculated. Each row represents the weight of individual factors. The g-DANP has given the global importance of factors and summarized them with priority shown, as in Table 3.

\section{[Insert Table 3]}

[Insert Table 4] 


\section{Results and Discussion}

\subsection{Overall Cause and Effect Analysis}

The total influence analysis of the main factors (dimensions) is shown; government policy and regulations $(\mathrm{G})$, behavioural factors $(\mathrm{B})$ and technological and infrastructural factors $(\mathrm{T})$ fall in the cause category. In contrast, operational factors come under the effect category. This shows that " $\mathrm{O}$ " is a dimension that is highly influenced, whereas " $\mathrm{G}$ ", " $\mathrm{B}$ " and " $\mathrm{T}$ " are the profoundly influencing dimensions. Figure IV represents the graphical relationship between the main factors. The prominence values from Table III shows that operational factor $(\mathrm{O})$ obtained the highest score (0.458). The high prominence is a sign of the high influence of the factor on PFSCs. Therefore, "O" should be considered as the most crucial factor to improve PFSCs during the pandemic. Similarly, values mean that nine sub-factors have been classified into the cause group with thirteen sub-factors in the effect group. The ranking for the cause group $i$. This shows that 'Nation-wide lockdown (G3)' is the causal factor that most hinders the perishable food supply chain. Similarly, from the values of price variation of perishable products (O2), poor delivery reliability (O5), fear of violation of social distancing guidelines (B3), cash flow constraints $(\mathrm{O} 3)$, and production shutdown $(\mathrm{O} 1)$ are the most crucial factors with importance degrees of 2.816, 2.795, 2.529, 2.454 and 2.448 respectively. Figure IV highlights the overall influence relationship map of the combined elements. In the next sub-sections, specific factor cause and effect analyses are presented.

\section{[Insert Figure IV]}

\subsection{Dimension Wise Cause and Effect Analysis}

\subsubsection{Operational Factors}

Referring to Table III cause and effect group of the "O" category, it can be seen that all subfactors come under the effect group. The ranking of sub-factors based on their prominence values are as follows; price variation of perishable products $(\mathrm{O} 2)$, poor delivery reliability $(\mathrm{O} 5)$, cash flow constraints (O3), production shutdown (O1) and inadequate capability to fulfil 
customer orders (O4); their values are 2.816, 2.795, 2.454, 2.448, 2.42 and 2.239 respectively. This shows that the price variation of perishable products is the significant operational factor affecting PFSC during the pandemic. The second important finding is that improved delivery reliability and proper cash flow can reduce the effect of the epidemic on PFSCs.

\subsubsection{Behavioural Factors}

The "B" category of factors (Table III) shows that two sub-factors are in the cause group and three in the effect group. The cause group elements are fear of violation of social distancing guidelines (B3), proactive health-minded buying (B4); panic buying and stockpiling (B1), consumer sentiments (B2) and less physical buying (B5) fall into the effect group. The above causal relationships clearly show that fear of violation of social distancing guidelines and proactive health-minded buying will significantly affect PFSCs. From the prominence values of the sub-factors, fear of violation of social distancing guidelines (B3), panic buying and stockpiling (B1), and consumer sentiments (B2) have highest values of 2.529, 2.327 and 2.151 respectively. These results conclude that strict rules for proper implantation of social distancing norms and adequate customer coordination would improve the status of PFSC.

\subsubsection{Government Policy and Regulations}

In the dimension "G" (refer to Table III), nation-wide lockdown (G3), restriction on importexport (G2), lack of policies for poultry, marine products and dairy farmers (G4), sealing of state borders due to lockdown (G5) and scarcity of workforce (G6) are the causal factors. In contrast, closure or limited operation of mandis (G1) falls in the effect group. The prominence analysis of the above sub-factors shows that nation-wide lockdown (G3), sealing of state borders due to lockdown (G5) and scarcity of workforce (G6) have highest values of 2.44, 2.237 and 2.193 respectively. From the above analysis, we recommend easing the nationwide lockdown and also providing workers with job security to maintain PFSCs functioning.

\subsubsection{Technological and Infrastructural Factors}

In this dimension (refer to Table III), inter-relationship analysis shows poor transportation network (T1) and information distortion (T4) as causal factors; technical difficulties in delivering perishable products with minimum human contact (T2), low area coverage of e-commerce platforms for perishable goods (T3) and poor packaging capabilities (T5) fall in the effect group. 
The above finding is fascinating in the case of the Indian PFSC because of the nature of the Indian market. Some experts claim that due to the physical buying habits of Indians, organizations need to work harder to develop their technological and infrastructural facilities to enhance customer affinity for new ways of buying goods. Based on values, the sub-factors T3 and T4 have highest importance values of 2.357 and 2.184 respectively

\subsection{Prioritisation of Factors Based on g-DANP}

When considering the factors affecting PFSCs during the pandemic as a multi-dimensional problem due to the involvement of multiple partners, a single model is not capable of explaining the analysis. To address the disadvantage of the DEMATEL technique to compute the dimensional relationship and computation of importance weight, g-DANP methodology is introduced. Table VII demonstrates the importance of the weight of each dimension and the respective sub-factors. The computation of the local importance weight of each sub-factor is formulated by dividing global weight by dimension weight. Referring to the importance weight (Table VII), price variation of perishable products $(\mathrm{O} 2)$, panic buying and stockpiling (B1), poor delivery reliability (O5), low area coverage of e-commerce platforms for perishable goods (T3) and inadequate capability to fulfil customers' orders $(\mathrm{O} 4)$ are the five top sub-factors affecting PFSC during the pandemic. The priority weight of the dimensions and sub-factors enable policymakers and managers to use this study as a benchmark to make necessary policy amendments to improve PFSCs. Table 4 depicts more precise data for developing improvement strategies. For example, region 1 (cause group) with high weight shows that restriction on import-export (G2) is the highest influential factor on PFSCs. This means that policymakers need to find ways to improve the guidelines on import-export to reduce the disruption caused to PFSCs during the pandemic. Similarly, from region 3 (effect-high group), price variation of perishable products $(\mathrm{O} 2)$, panic buying and stockpiling (B1) and poor delivery reliability (O5) are the chief effect group factors.

\section{Implications for Practice and Research}

The proposed g-DANP evaluation framework can be used by managers of PFSCs to gain a more valid assessment of factors and develop a strategic plan to maintain PFSCs during pandemics. By synthesising expert opinion, an integration of grey DEMATEL into ANP was used to determine the causal relationships and importance weights of the factors; a strategic framework was thus 
developed. Many valuable managerial insights can be drawn from cause-effect diagrams, and the converged super-matrix. The managerial implications of this study are:

i. If PFSC policymakers and managers wish to obtain high performance in the "effect factors", our recommendation is to increase attention and control to the "cause factors" as the cause factors have more influence. The computational analysis of inter-relationships shows that price variation of perishable products $(\mathrm{O} 2)$ is the most crucial factor among the twenty-two factors. Therefore, policymakers and managers should propose appropriate policy measures to improve the price variation.

ii. The research findings of this study provide a priority list of factors. Policymakers can use this list to develop strategic policies to reduce disturbances caused to PFSCs.

iii. From a theoretical perspective, this paper develops a hierarchical structure for analysing the impact of the pandemic on PFSCs. In reality, some developing nations like India have lacked a basic structure for decision making; the structure can assist in setting priorities and improving the decision-making process.

iv. The weights formulated in this research can be helpful to different PFSCs to check the factor weightage in their processes. The factors can be compared based on their weight values and can then be ranked accordingly for a specific perishable food company.

\section{Concluding Remarks}

The effect of the pandemic on various SCs is a critical research area; it is necessary to provide more in-depth analysis for future development. PFSC has become a priority area for policymakers and managers over the last few months, mainly because of its importance in providing essential items to the general population. The analysis of the factors influencing PFSCs during the pandemic is needed to improve the condition of the perishable sector. In an intricate decision-making and assessment process, there are numerous factors which incorporate subjective and qualitative judgments. In such circumstances, MCDM techniques can be adequately utilized to process coefficients, inter-relationships and to prioritize their importance. This paper has developed a hierarchical model based on the factors affecting PFSC during the pandemic. The analysis of the proposed structure is performed by utilizing a coordinated MCDM technique i.e., grey-DEMATEL-ANP (g-DANP). The proposed structure is validated with an empirical data set of PFSC factors during the recent COVID-19 outbreak. Experts from three 
different sectors were consulted - F.C.I., perishable product companies plus logistics and supply chain academicians. The computational result confirms that the proposed model can help policymakers and practitioners in improving their decision-making processes to enhance the perishable food supply chain, specifically in cases when several factors are inter-related.

The computational results are introduced in two parts; first, an inter-relationship among the dimensions are shown. Second, the significant weight of factors are formulated to visualise the most crucial elements, and in the interim, policymakers make appropriate strategies to improve the perishable food sector. The grey-DEMATEL approach is utilized to recognize the interrelationships among selected dimensions and their sub-factors. After that, a g-DANP technique is used to register the significance of weight. Their inter-dependence, in the form of cause and effect, is presented through an influence relation map (IRM) (Figure IV). The priority area of policy implementation is determined by factor influence; policymakers and managers may consider this when evaluating performance of the PFSC during the epidemic.

To enhance the computational effectiveness of ANP, an integration of grey-DEMATEL and ANP was used to provide successful results in reaching strategic decisions. The present study also accentuated that there is no similar study that identifies the factors affecting PFSCs during the pandemic utilizing these procedures. Therefore, this paper fills this research gap by using a novel g-DANP approach to recognize the inter-relationships and significance of weight.

The limitation of this study is its dependence on judgmental data from humans (experts). Future studies can be validated and compared to our results by gauging importance of the decisionmakers i.e. using intuitionistic fuzzy or grey environment. The second limitation of the present work is that all specialists are taken together; further studies can be considered with individual partners to check the comparability and differences in the decision-making process.

\section{Acknowledgements}

The authors would like to express their gratitude towards the industry expert members for their valuable support in evaluating the proposed framework. The authors would also like to thank $\mathrm{Mr}$ Soliman Amini, manager at www.sanaye20.ir for giving supporting material for the research. Also, the first author would like to thank Mr Rahul Jain, Scholar, Indian Institute of Technology, Delhi, India, for providing python script to verify the calculations.

\section{References}


Abikova, J. 2020. Application of fuzzy DEMATEL-ANP methods for siting refugee camps. Journal of Humanitarian Logistics and Supply Chain Management,DOI: https://doi.org/10.1108/JHLSCM12-2018-0078

Affairs, M. O. H. 2020. No. 40-3/2020-DM-I(A) [Online]. New Delhi: Government of India. [Accessed].

Aggarwal, S. \& Srivastava, M. K. 2016. Towards a grounded view of collaboration in Indian agri-food supply chains: a qualitative investigation. British Food Journal, 118.

Albertzeth, G., Pujawan, I. N., Hilletofth, P. \& Tjahjono, B. 2020. Mitigating transportation disruptions in a supply chain: a cost-effective strategy. International Journal of Logistics Research and Applications, 23, 139-158.

Badakhshan, E., Humphreys, P., Maguire, L. \& Mcivor, R. 2020. Using simulation-based system dynamics and genetic algorithms to reduce the cash flow bullwhip in the supply chain. International Journal of Production Research. DOI:https://doi.org/10.1080/00207543.2020.1715505

Balaji, M. \& Arshinder, K. 2016. Modeling the causes of food wastage in Indian perishable food supply chain. Resources, Conservation and Recycling, 114, 153-167.

Bharti, A. \& Mittal, A. 2018. Perishable goods supply cold chain management in India. Supply Chain Management Strategies and Risk Assessment in Retail Environments. IGI Global.

Bhosale, J. 2020. Prices of agricultural commodities drop 20\% post COVID-19 outbreak. Available: https://economictimes.indiatimes.com/news/economy/agriculture/prices-of-agriculturalcommodities-drop-20-post-covid-19-outbreak/ [Accessed March 19].

Bhosale, J. \& Sally, M. 2020. Covid-19 impact: Fearful vegetable mandis threaten to shut shop. Available: https://economictimes.indiatimes.com/news/politics-and-nation/fearful-vegetablemandis-threaten-to-shut-shop/ [Accessed March 24].

Birthal, P. S., Hazrana, J. \& S.Negi, D. 2020. Diversification in Indian agriculture towards high value crops: Multilevel determinants and policy implications. Land Use Policy, 91, DOI: https://doi.org/10.1016/j.landusepol.2019.104427.

Bora, G. 2020. Covid-19: In the times of 'touch-me-not' environment, drones are the new best friends [Online]. E.T. Rise. Available: https://economictimes.indiatimes.com/smallbiz/startups/features/covid-19-in-the-times-of-touch-me-not-environment-drones-are-the-newbest-friends/ [Accessed May 2020].

Brown, M. J. \& Goodwin, J. 2020. Allocating Medical Resources in the Time of Covid-19. The New England Journal of Medicine, DOI: 10.1056/NEJMc2009666.

Büyüközkan, G. \& Güleryüz, S. 2016. An integrated DEMATEL-ANP approach for renewable energy resources selection in Turkey. International Journal of Production Economics, 182, 435-448.

Büyüközkan, G., Güleryüz, S. \& Karpak, B. 2017. A new combined IF-DEMATEL and IF-ANP approach for CRM partner evaluation. International Journal of Production Economics, 191, 194206.

Cattini, C. 2017. Food Trends in India [Online]. IFIS Food and Health Information. Available: https://www.ifis.org/blog/food-trends-in-india [Accessed 2020].

Chen, S., Brahma, S., Mackay, J., Cao, C. \& Aliakbarian, B. 2020. The role of smart packaging system in food supply chain. Journal of Food Science, 85, 517-525, DOI: https://doi.org/10.1111/17503841.15046.

Chowdhury, A. 2020. Logistics costs set to rise as freighters hike tariffs [Online]. Mumbai: The EconomicTimes

Available: https://economictimes.indiatimes.com/industry/transportation/shipping-/-transport/logistics-costsset-to-rise-as-freighters-hike-tariffs/articleshow/75129422.cms [Accessed 2020].

Dagne, T. B., Jayaprkash, J. \& Gebeyehu, S. G. 2020. Design of Supply Chain Network Model for Perishable Products with Stochastic Demand: An Optimized Model. Journal of Optimization in Industrial Engineering, 13, 29-37, DOI: 10.22094/JOIE.2019.563130.1551.

Demirel, T., Demirel, N. Ç. \& Kahraman, C. 2010. Multi-criteria warehouse location selection using Choquet integral. Expert Systems with Applications, 37, 3943-3952. 
Dev, S. M. \& Sengupt, R. 2020. Covid-19: Impact on the Indian Economy. Mumbai: Indira Gandhi Institute of Development Research.

Dhanaselvi, S. \& Gayathri, T. 2019. A Study on Production and Marketing of Poultry Eggs in TamilnaduIndia. A Journal Of Composition Theory, 12, 1323-1333.

Division, F. F. P. 2019. Food Processing. India: Federation of Indian Chambers of Commerce and Industry.

Dmitryivanov 2020. Predicting the impacts of epidemic outbreaks on global supply chains: A simulationbased analysis on the coronavirus outbreak (COVID-19/SARS-CoV-2) case. Transportation Research Part E: Logistics and Transportation Review, 136, 19-22.

Dolgui, A., Ivanov, D. \& Rozhkov, M. 2020. Does the ripple effect influence the bullwhip effect? An integrated analysis of structural and operational dynamics in the supply chain. Int. J. Prod. Res., $58,1285-1301$.

Dyal, J. W. 2020. COVID-19 Among Workers in Meat and Poultry Processing Facilities-19 States, April 2020. MMWR. Morbidity and Mortality Weekly Report, 69.

Farooque, M., Zhang, A. \& Liu, Y. 2019. Barriers to circular food supply chains in China. Supply Chain Management: An International Journal, 24, 677-696.

Fernandes, N. 2020. Economic effects of coronavirus outbreak (COVID-19) on the world economy Spain: IESE Business School

Fiorini, M., Hoekman, B. \& Yildirim, A. 2020. COVID-19: Expanding access to essential supplies in a value chain world. COVID-19 and Trade Policy: Why Turning Inward Won't Work, 63.

Fischlmayr, I. C. 2009. A training design for behavioral factors in virtual multicultural teams. Handbook of Research on Electronic Collaboration and Organizational Synergy. IGI Global.

Fortune. 2020. Coronavirus China Supply Chain Impact [Online]. Available: https://fortune.com/2020/02/21/fortune-1000-coronavirus-china-supply-chain-impact/] [Accessed April 2020].

Fund, I. M. 2020. World Economic Outlook Database.

Gabus, A. \& Fontela, E. World Problems, an Invitation to Further Thought within the Framework of DEMATEL. 1972 Geneva, Switzerland. Battelle Geneva Research Center.

Ghosal, S. 2020. Covid-19 lockdown has severely hit the poultry industry with Q4 being the worst quarter:ICRA [Online]. The Economic Times. Available: https://economictimes.indiatimes.com/news/economy/agriculture/covid-19-lockdown-hasseverely-hit-the-poultry-industry-with-q4-being-the-worst-quartericra/ [Accessed April 2020].

Goel, R. \& Yadav, K. 2020. Poultry Prices Skid in India Due to Fake News Circulation on Coronavirus. SocArXiv, DOI: https://doi.org/10.31235/osf.io/9gq6n.

Gölcük, İ. \& Baykasoğlu, A. 2016. An analysis of DEMATEL approaches for criteria interaction handling within ANP. Expert Systems with Applications, 46, 346-366.

Goldbeck, N., Angeloudis, P. \& Ochieng, W. 2020. Optimal supply chain resilience with consideration of failure propagation and repair logistics. Transportation Res. Part E: Logistics Transportation Rev., 133, 18-30.

Govindan, K., Jafarian, A., Khodaverdi, R. \& Devika, K. 2014. Two-echelon multiple-vehicle locationrouting problem with time windows for optimization of sustainable supply chain network of perishable food. International Journal of Production Economics, 152, 9-28.

Govindan, K., Shankar, M. \& Kannan, D. 2018. Supplier selection based on corporate social responsibility practices. International Journal of Production Economics, 200, 353-379.

Govindan, K., Muduli, K., Devika, K., and Barve, A. 2016 Investigation of the influential strength of factors on adoption of green supply chain management practices: An Indian mining scenario, Resources, Conservation and Recycling,107, 185-194

Gray, R. S. 2020. Agriculture, transportation, and the COVID-19 crisis. Canadian Journal of Agricultural Economics/Revue canadienne d'agroeconomie.

Grunow, M. \& Piramuthu, S. 2013. RFID in highly perishable food supply chains - Remaining shelf life to supplant expiry date? International Journal of Production Economics, 146, 717-727. 
Halder, P. \& Pati, S. 2011. A Need For Paradigm Shift to Improve Supply Chain Management of Fruits \& Vegetables in India. Asian Journal of Agriculture and Rural Development, 1, 1-20.

Hasani, A., Zegordi, S. H. \& Nikbakhsh, E. 2015. Robust closed-loop global supply chain network design under uncertainty: the case of the medical device industry. International Journal of Production Research, 53, 1596-1624.

India, G. O. 2015. National Agriculture Market [Online]. Available: https://enam.gov.in/web/stakeholders-Involved/Apmcs [Accessed 2020].

Ivanov, D., Dolgui, A., Sokolov, B. \& Ivanova, M. 2017. Literature review on disruption recovery in the supply chain. Int. J. Production Research, 55, 6158-6174.

Joyce Mazero \& Macphee, L. L. 2020. COVID 19 and Supply Chain Contracts [Online]. National Law Review. Available: https://www.natlawreview.com/article/covid-19-and-supply-chain-contracts [Accessed April 2020].

Ju-Long, D. 1982. Control problems of grey systems. Systems \& Control Letters, 1, 288-294.

Kamal, N. 2020. Punjab farmers start dumping vegetables due to curfew. Available: https://timesofindia.indiatimes.com/city/chandigarh/punjab-farmers-start-dumping-vegetablesdue-to-curfew/ [Accessed March 25].

Khanna, R. \& Pande, J. M. 2020. Kolkata: Sweet shops closed, 2 lakh litre fresh milk going d .. Available: https:/timesofindia.indiatimes.com/city/kolkata/kolkata-sweet-shops-closed-2-lakhlitre-fresh-milk-going-down-the-drain-every-day/ [Accessed March 28].

Kinra, A., Ivanov, D., Das, A. \& Dolgui, A. 2019. Ripple effect quantification by supply risk exposure assessment. Int. J. Production Research, DOI: 10.1080/00207543.2019.1675919.

Kumar, A. \& Anbanandam, R. 2020. Analyzing interrelationships and prioritising the factors influencing sustainable intermodal freight transport system: A grey-DANP approach. Journal of Cleaner Production, 252, DOI: https://doi.org/10.1016/j.jclepro.2019.119769.

Kumar, A., Mangla, S. K., Kumar, P. \& Karamperidis, S. 2020. Challenges in perishable food supply chains for sustainability management: A developing economy perspective. Business Strategy and the Environment, 29, 1809-1831.

Kumar, P. \& Grover, N. 2020. COVID-19 [Online]. National Restaurant Association of India. Available: https://nrai.org/ [Accessed 2020].

Kumar, R. 2020. Organizational Performance through Dairy Supply Chain Management Practices: A Winning Approach. Supply Chain and Logistics Management: Concepts, Methodologies, Tools, and Applications. IGI-global.

Leena Jaisani, Ankit Shukla \& Malik, R. 2017. Indian Food Services Industry: Engine for Economic Growth \& Employment. Federation of Indian Chambers of Commerce and Industry.

Li, X. \& He, Z. 2020. An integrated approach for evaluating hospital service quality with linguistic preferences. International Journal of Production Research. DOI: https://doi.org/10.1080/00207543.2020.1725681

Li, Y., Diabat, A. \& Lu, C.-C. 2020. Leagile supplier selection in Chinese textile industries: a DEMATEL approach. Annals of Operations Research, 287, 303-322.

Lima-Junior, F. R. \& Carpinetti, L. C. R. 2020. An adaptive network-based fuzzy inference system to supply chain performance evaluation based on SCOR ${ }^{\circledR}$ metrics. Computers \& Industrial Engineering, 139, 106191.

Lyngstadaas, H. 2019. An empirical investigation of how information sharing affects cash flow performance through competitive capability. Supply Chain Management: An International Journal, 24, 710-728.

Martin-Neuninger, R. \& Ruby, M. 2020. What does food retail research tell us about the implications of COVID-19 for grocery purchasing habits? DOI: 10.31234/osf.io/z2kup.

Ministry of Consumer Affairs, F. P. D. 2020. Essential Commodities [Online]. New Delhi: Government of India. [Accessed].

Mohfw. 2020. COVID-19 INDIA [Online]. Ministry of Health and Family Welfare, Government of India. Available: https://www.mohfw.gov.in/ [Accessed June 2020]. 
Mor Rahul, S., Bhardwaj, A. \& Singh, S. 2018. Benchmarking the interactions among performance indicators in dairy supply chain: An ISM approach. Benchmarking: An International Journal, 25, 3858-3881.

Nakandala, D. \& Lau, H. C. W. 2019. Innovative adoption of hybrid supply chain strategies in urban local fresh food supply chain. Supply Chain Management: An International Journal, 24, 241-255.

News, F. 2020. Consumer spending is down. Will we continue to buy less stuff? [Online]. Futurity Available: https://medium.com/@,Futurity/consumer-spending-is-down-will-we-continue-to-buyless-stuff-d9efefb0b2b1 [Accessed April 2020].

Notebaert, L. 2020. COVID-19: The psychology of panic buying. The University of Western Australia. Available at: http://www.news.uwa.edu.au/2020042812028/uwa-public-policy-institute/covid-19psychology-panic-buying.

Opricovic, S. \& Tzeng, G.-H. 2003. DEFUZZIFICATION WITHIN A MULTICRITERIA DECISION MODEL. International Journal of Uncertainty, Fuzziness and Knowledge-Based Systems, 11, 635-652.

Organization, W. H. 2020. Coronavirus disease (COVID-19) advice for the public [Online]. Available: https://www.who.int/emergencies/diseases/novel-coronavirus-2019/advice-for-public [Accessed April 2020].

Özkan, B., Özceylan, E., \& Çetinkaya, C. (2019). A GIS-based DANP-VIKOR approach to evaluate R\&D performance of Turkish cities. Kybernetes. 48 (10): 2266-2306.

Peermohamed, A. 2020. Covid-19 impact: From BigBasket to Grofers, mounting orders and staff crunch stretch online grocers [Online]. E.T. Rise. Available: https:/economictimes.indiatimes.com/small-biz/startups/newsbuzz/covid-19-impact-frombigbasket-to-grofers-mounting-orders-and-staff-crunch-stretch-online-grocers/ [Accessed 2020].

Prakash, R. R., Sreedhar, U., Rao, B. M., Viji, P., Debbarma, J., Kamei, G. \& Basha, A. 2020. COVID-19 Mitigation Advisories for Harvest and Post Harvest Sector of Indian Fisheries. Kochi: ICARCIFT.

Prakash, S., Soni, G., Rathore Ajay Pal, S. \& Singh, S. 2017. Risk analysis and mitigation for perishable food supply chain: a case of dairy industry. Benchmarking: An International Journal, 24, 2-23.

Rahimnia, F., Moghadasian, M. \& Mashreghi, E. 2011. Application of grey theory approach to evaluation of organizational vision. Grey Systems: Theory and Application, 1, 33-46.

Raj, A. \& Sah, B. 2019. Analyzing critical success factors for implementation of drones in the logistics sector using grey-DEMATEL based approach. Computers \& Industrial Engineering, 138, 106118.

Raj, G. V. 2020. COVID-19 impact: Tough times for poultry farmers as prices crash by $60 \%$. Available: https://www.deccanherald.com/state/karnataka-districts/covid-19-impact-tough-times-forpoultry-farmers-as-prices-crash-by-60-811297.html [Accessed March].

Ramaswami, B., Birthal, P. S. \& Joshi, P. K. 2006. Efficiency and Distribution in Contract Farming: The Case of Indian Poultry Growers Available: http://ageconsearch.umn.edu/record/58573/files/mtidp91.pdf.

Reardon, T., Bellemare, M. F. \& Zilberman, D. 2020. How COVID-19 may disrupt food supply chains in developing countries? IFPRI book chapters, in: COVID-19 and global food security. International Food Policy Research Institute (IFPRI).

Reddy, A. 2020. The Pandemic Is Amplifying India's Fake News Crisis. Available: https://thewire.in/media/medical-fake-news-coronavirus [Accessed April 2].

Reinhart, C. M. \& Subbaraman, R. 2020. Preventing a COVID-19 Food Crisis [Online]. Project Syndicate Available: https://www.project-syndicate.org/commentary/governments-must-preventcovid19-food-crisis-by-carmen-reinhart-2020-05 [Accessed 2020].

Rosales Fabricio, P., Oprime Pedro, C., Royer, A. \& Batalha Mario, O. 2019. Supply chain risks: findings from Brazilian slaughterhouses. Supply Chain Management: An International Journal, 25, 343357. 
Rossi, T., Pozzi, R., Pirovano, G., Cigolini, R. \& Pero, M. 2020. A new logistics model for increasing economic sustainability of perishable food supply chains through intermodal transportation. International Journal of Logistics Research and Applications. DOI: https://doi.org/10.1080/13675567.2020.1758047

Routroy, S. \& Behera, A. 2017. Agriculture supply chain: A systematic review of literature and implications for future research. Journal of Agribusiness in Developing and Emerging Economies, 7, 275-302.

Roy, D., Tripathy, S., Kar, S. K., Sharma, N., Verma, S. K. \& Kaushal, V. 2020. Study of knowledge, attitude, anxiety \& perceived mental healthcare need in Indian population during COVID-19 pandemic. Asian Journal of Psychiatry, 51, 102083.

Sanders, N. R. 2020. Covid-19 Supply-Chain Disruption [Online]. Treasury \& Risk. Available: https://www.treasuryandrisk.com/2020/03/19/covid-19-supply-chain-disruption/? slreturn=20200426104741 [Accessed April 2020].

Schulte-Mecklenbeck, M., Sohn, M., De Bellis, E., Martin, N. \& Hertwig, R. 2013. A Lack of Appetite for Information and Computation. Simple Heuristics in Food Choice. Appetite, 71, 242-251.

Shukla, M. \& Jharkharia, S. 2013. Agri-fresh produce supply chain management: a state-of-the-art literature review. International Journal of Operations \& Production Management, 33, 114-158.

Sim, K., Chua, H. C., Vieta, E. \& Fernandez, G. 2020. The anatomy of panic buying related to the current COVID-19 pandemic. Psychiatry Research, DOI: 10.1016/j.psychres.2020.113015.

Singh, R. \& Bhanot, N. 2020. An integrated DEMATEL-MMDE-ISM based approach for analysing the barriers of IoT implementation in the manufacturing industry. International Journal of Production Research, 58, 2454-2476.

Singh, S., Kumar, R., Panchal, R. \& Tiwari, M. K. 2020. Impact of COVID-19 on logistics systems and disruptions in food supply chain. International Journal of Production Research. DOI: ttps://doi.org/10.1080/00207543.2020.1792000

Sinha, A. K. \& Anand, A. 2020. Optimizing supply chain network for perishable products using improved bacteria foraging algorithm. Applied Soft Computing,DOI: https://doi.org/10.1016/j.asoc.2019.105921.

Supeekit, T., Somboonwiwat, T. \& Kritchanchai, D. 2016. DEMATEL-modified ANP to evaluate internal hospital supply chain performance. Computers \& Industrial Engineering, 102, 318-330.

Suri, R. \& Monroe, K. 2003. The Effects of Time Constraints on Consumers' Judgments of Prices and Products. Journal of Consumer Research, 30, 92-104.

Swierczek, A. \& Szozda, N. 2019. Demand planning as a tamer and trigger of operational risk disruptions: evidence from the European supply chains. Supply Chain Management: An International Journal, 24, 748-766.

Tadić, S., Zečević, S. \& Krstić, M. 2014. A novel hybrid MCDM model based on fuzzy DEMATEL, fuzzy ANP and fuzzy VIKOR for city logistics concept selection. Expert Systems with Applications, 41, 8112-8128.

Thind, J. 2020. How e-commerce platforms are lending a new lease of life to offline retailers in the face of Covid-19 [Online]. E.T. Rise. Available: https://economictimes.indiatimes.com/smallbiz/startups/newsbuzz/how-e-commerce-platforms-are-lending-a-new-lease-of-life-to-offlineretailers-in-the-face-of-covid-19/ [Accessed 2020].

Thornton, G. 2017. Food processing sector: Challenges and growth enablers. New Delhi: Associated Chambers of Commerce and Industry of India

Tilotia, A. 2020. How social distancing disrupts supply-chains [Online]. Financial Express - Business News, Stock Market News. Available: https://www.financialexpress.com/opinion/coronavirusnews-sars-cov-2-how-social-distancing-disrupts-supply-chains/1903938/ [Accessed April 2020].

Tran, T. M. T., Yuen, K. F., Li, K. X., Balci, G. \& Ma, F. 2020. A theory-driven identification and ranking of the critical success factors of sustainable shipping management. Journal of Cleaner Production, 243, 118401. 
Tropics, I. C. R. I. F. T. S.-A. 2020. Agri-Buzz: CONTAINING COVID19 IMPACTS ON INDIAN AGRICULTURE [Online]. Available: https://www.icrisat.org/containing-covid19-impacts-onindian-agriculture/ [Accessed April 2020].

Tseng, M.-L. 2009. A causal and effect decision making model of service quality expectation using greyfuzzy DEMATEL approach. Expert Systems with Applications, 36, 7738-7748.

Vaid, S. K. 2020. An Overview of Indian Agriculture with Focus on Challenges and Opportunities in North East. In: R., G., R., S. \& D., S. (eds.) Microbiological Advancements for Higher Altitude Agro-Ecosystems \& Sustainability. Singapore: Springer.

Wang, C., Pan, R., Wan, X., Tan, Y., Xu, L., Mcintyre, R. S., Choo, F. N., Tran, B., Ho, R. \& Sharma, V. K. 2020. A longitudinal study on the mental health of general population during the COVID-19 epidemic in China. Brain, behavior, and immunity, DOI: https://doi.org/10.1016/j.bbi.2020.04.028.

Wasdani, K. P. \& Prasad, A. 2020. The impossibility of social distancing among the urban poor: the case of an Indian slum in the times of COVID-19. Local Environment, 25, 414-418.

Willem, A. R., Rossi, R. \& Jack, G. a. J. V. D. V. 2014. Effective sourcing strategies for perishable product supply chains. International Journal of Physical Distribution \& Logistics Management, 44, 494-510.

Williams, F. 2019. The Effects of Government Policies on Businesses [Online]. Chron. Available: https://smallbusiness.chron.com/effects-government-policies-businesses-65214.html\# [Accessed March 2020].

Xu, S., Zhang, X., Feng, L. \& Yang, W. 2020. Disruption risks in supply chain management: a literature review based on bibliometric analysis. Int. J. Prod. Res., DOI: 10.1080/00207543.2020.1717011.

Yan, R. 2017. Optimization approach for increasing revenue of perishable product supply chain with the Internet of Things. Industrial Management \& Data Systems, 117, 729-741. 
Appendix A: A hybrid MCDM model combined with Grey-DEMATEL and ANP

\section{Grey-DEMATEL Method:}

The Grey-DEMATEL method having the following steps;

Step 1: Compute the direct relation matrix

The initial information is obtained from the specialists are presented in direct relation matrix of, matrix , where every component is indicated as the relationship degree as the impact of component over . Let us consider, characterized as the grey number for a specialist, which gives assessment data of factor on factor. Then, and are the upperand lower estimations of a given number, i.e.,

Step 2: Calculation of the average grey relation matrix (AGRM)

The AGRM is formulated from grey relation matrices as,

Step 3: Formulation of crisp relation matrix

In this formulation, a defuzzification technique is applied to change grey relation to crisp relation by using to convert fuzzy data into the crisp score (CFCS) strategy (Opricovic and Tzeng, 2003). The crisp transformation follows a three-stage technique:

i. Normalization:

Where defined as the normalized upper limit of a given grey number, and

Where represents the lower value of the given grey number .

The value of is calculated as follows; 
ii. Formulation of the total normalized crisp value;

iii. Calculate the final crisp values;

And,

Step 4: Formulate the normalized direct crisp relation matrix by

Let be a normalized crisp relation matrix, then;

Where is a normalization factor given by;

Step 5: Compute the total relation matrix $(\mathrm{T})$ by

Where, is the identity matrix and is the corresponding values in matrix .

Step 6: Formulate the Prominence and Relation of Each Factor

Where, and represents the sum of the ith row elements and the sum of jth column elements in respectively.

When, is the "Prominence" which shows the importance degree that factor plays in the entire analysis. Similarly, is called "Relation" that depicts the overall effect of that factor contributes towards the entire system.

Step 7: Calculate the total relationship matrix 


\section{Integration of Grey-DEMATEL and ANP Methods:}

Step 1: Calculate an unweighted super-matrix

and are the total influence matrix of main factors (Dimensions) and sub-factors (criteria) respectively, which obtained by the grey-DEMATEL method.

Let be given by equation 13;
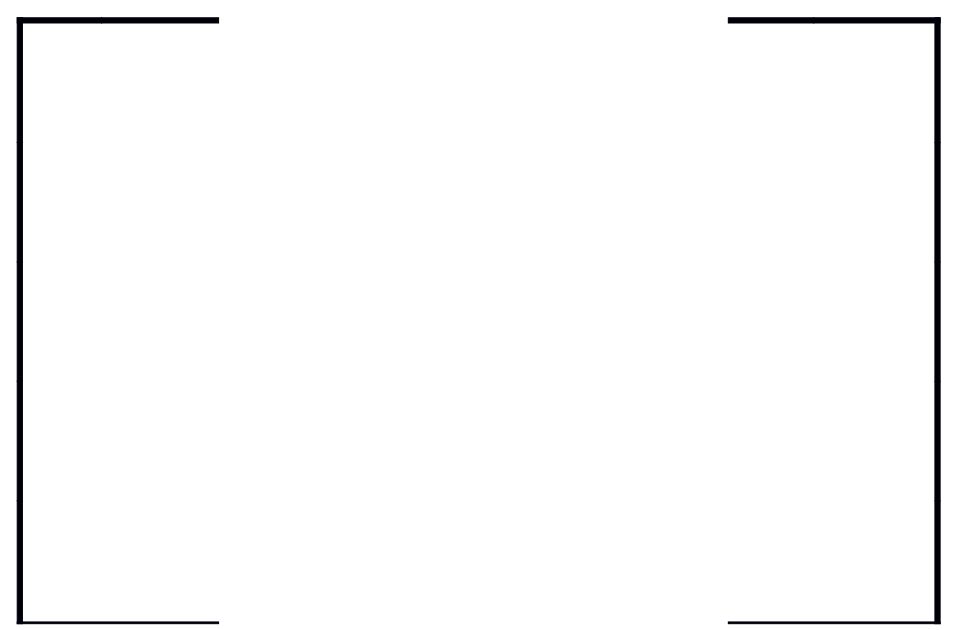

The normalized TRM for criteria is denoted as, which is obtained from normalizing the total influence matrix of criteria, is given by equation 14;

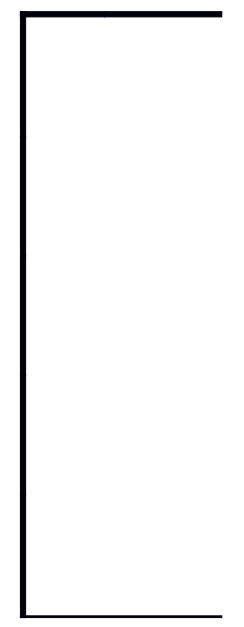


Normalized element is explicated in detail in equation 15 and 16;

For formulating unweighted super-matrix, the normalized TRM for criteria is transposed as shown in equation 17;
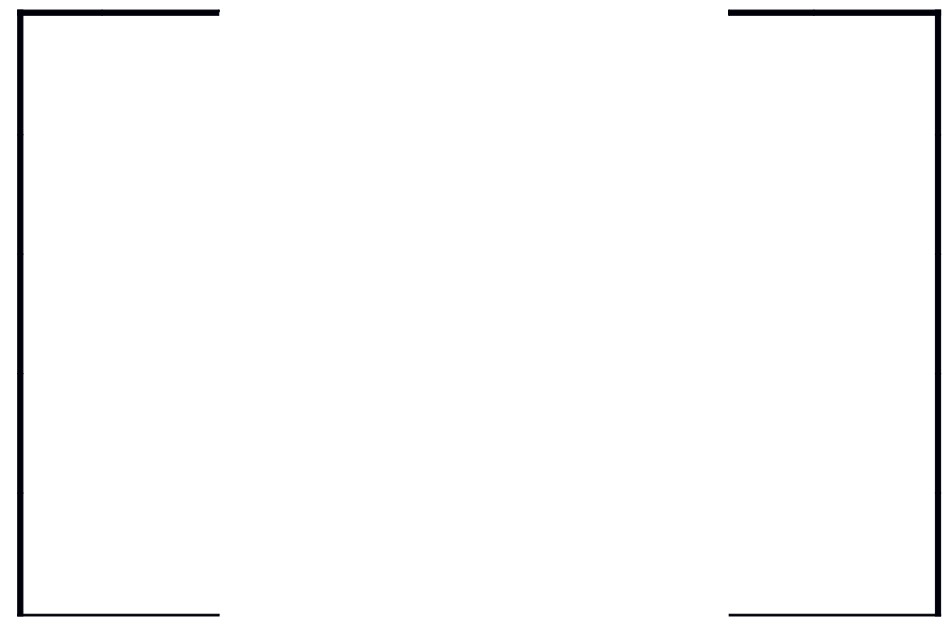

(0)

Where,

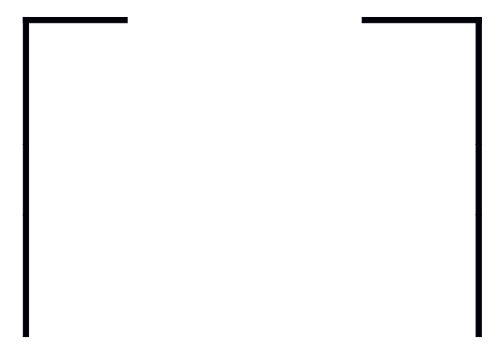




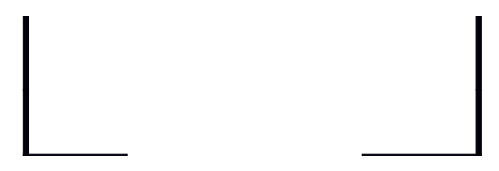

Step 2: Calculate the Weighted Super-matrix

To calculate the weighted super-matrix, the TRM for main factors (Dimensions) were considered as shown in equation 19;

Then, normalisation of TRM ' ' is done and a new matrix "' is obtained as shown in equation 20;

The weighted super-matrix () is obtained with the help of equation 21;

Step 3: Limit the weighted super-matrix.

To acquire a stable and converged matrix, the weighted super-matrix which we got in the last step is to limit by expanding to a satisfactorily large power $\mathrm{k}$ until to fulfil the above prerequisites, which will finally result in global priority scores, which is called as grey-DANP (grey-DEMATEL based ANP) influential weights, such as, where represents any number of power (Govindan et al., 2018).

Table 1. The grey linguistics scale for experts' responses

\begin{tabular}{ccc}
\hline Linguistic terms & Grey range & Normal value \\
\hline No influence $(\mathrm{N})$ & {$[0.0,0.1]$} & 0 \\
\hline Very low influence & {$[0.1,0.3]$} & 1 \\
\hline Low influence $(\mathrm{L})$ & {$[0.2,0.5]$} & 2 \\
\hline Medium influence $(\mathrm{M})$ & {$[0.4,0.7]$} & 3
\end{tabular}




\begin{tabular}{ccc} 
High influence $(\mathrm{H})$ & {$[0.6,0.9]$} & 4 \\
\hline Very high influence $(\mathrm{VH})$ & {$[0.9,1.0]$} & 5 \\
\hline
\end{tabular}

Table 2. Influence Among Factors' Dimensions and Sub-factors

\begin{tabular}{|c|c|c|c|c|c|c|c|c|c|c|c|}
\hline & & & & & Nature & & & & & & Nature \\
\hline \multirow[t]{6}{*}{ O } & 0.142 & 0.316 & 0.458 & -0.174 & Effect & 01 & 0.907 & 1.541 & 2.448 & -0.634 & Effect \\
\hline & & & & & & O2 & 0.694 & 2.122 & 2.816 & -1.428 & Effect \\
\hline & & & & & & $\mathbf{O 3}$ & 0.886 & 1.568 & 2.454 & -0.682 & Effect \\
\hline & & & & & & 04 & 0.649 & 1.771 & 2.42 & -1.122 & Effect \\
\hline & & & & & & 05 & 0.885 & 1.91 & 2.795 & -1.025 & Effect \\
\hline & & & & & & 06 & 0.71 & 1.529 & 2.239 & -0.819 & Effect \\
\hline \multirow[t]{5}{*}{ B } & 0.206 & 0.187 & 0.393 & 0.019 & Cause & B1 & 0.603 & 1.724 & 2.327 & -1.121 & Effect \\
\hline & & & & & & B2 & 0.997 & 1.154 & 2.151 & -0.157 & Effect \\
\hline & & & & & & B3 & 1.923 & 0.606 & 2.529 & 1.317 & Cause \\
\hline & & & & & & B4 & 1.293 & 0.74 & 2.033 & 0.553 & Cause \\
\hline & & & & & & B5 & 0.895 & 0.924 & 1.819 & -0.029 & Effect \\
\hline \multirow[t]{6}{*}{ G } & 0.266 & 0.124 & 0.390 & 0.141 & Cause & G1 & 1.011 & 1.149 & 2.16 & -0.138 & Effect \\
\hline & & & & & & G2 & 1.063 & 1.003 & 2.066 & 0.06 & Cause \\
\hline & & & & & & G3 & 2.032 & 0.408 & 2.44 & 1.624 & Cause \\
\hline & & & & & & G4 & 1.45 & 0.349 & 1.799 & 1.101 & Cause \\
\hline & & & & & & G5 & 1.832 & 0.405 & 2.237 & 1.427 & Cause \\
\hline & & & & & & G6 & 1.427 & 0.766 & 2.193 & 0.661 & Cause \\
\hline \multirow[t]{5}{*}{$\mathbf{T}$} & 0.199 & 0.185 & 0.384 & 0.014 & Cause & T1 & 1.434 & 0.748 & 2.182 & 0.686 & Cause \\
\hline & & & & & & $\mathbf{T} 2$ & 1.044 & 1.068 & 2.112 & -0.024 & Effect \\
\hline & & & & & & T3 & 0.871 & 1.486 & 2.357 & -0.615 & Effect \\
\hline & & & & & & T4 & 1.432 & 0.752 & 2.184 & 0.68 & Cause \\
\hline & & & & & & T5 & 0.741 & 1.056 & 1.797 & -0.315 & Effect \\
\hline
\end{tabular}


Table 3 Importance of Weight Computation of Factors Through g-DANP

\begin{tabular}{|c|c|c|c|}
\hline Dimensions/Sub-Factors & Local Weight & Global Weight & Rank \\
\hline Operational Factors (O) & 0.391 & & 1 \\
\hline O1 & 0.1407 & 0.055 & 8 \\
\hline $\mathbf{O 2}$ & 0.212 & 0.083 & 1 \\
\hline $\mathbf{O 3}$ & 0.148 & 0.058 & 6 \\
\hline O4 & 0.164 & 0.064 & 5 \\
\hline $\mathbf{O 5}$ & 0.189 & 0.074 & 3 \\
\hline 06 & 0.146 & 0.057 & 7 \\
\hline Behavioural Factors (B) & 0.235 & & 2 \\
\hline B1 & 0.340 & 0.08 & 2 \\
\hline B2 & 0.221 & 0.052 & 9 \\
\hline B3 & 0.123 & 0.029 & 18 \\
\hline B4 & 0.153 & 0.036 & 15 \\
\hline B5 & 0.162 & 0.038 & 13 \\
\hline $\begin{array}{l}\text { Government Policy and Regulations } \\
\text { (G) }\end{array}$ & 0.152 & & 4 \\
\hline G1 & 0.283 & 0.043 & 12 \\
\hline G2 & 0.25 & 0.038 & 13 \\
\hline G3 & 0.112 & 0.017 & 20 \\
\hline G4 & 0.092 & 0.014 & 21 \\
\hline G5 & 0.092 & 0.014 & 21 \\
\hline G6 & 0.171 & 0.026 & 19 \\
\hline
\end{tabular}




\begin{tabular}{|c|c|c|c|}
\hline $\begin{array}{c}\text { Technological \& Infrastructural } \\
\text { Factors (T) }\end{array}$ & $\mathbf{0 . 2 2 2}$ & & $\mathbf{3}$ \\
\hline T1 & 0.135 & 0.03 & 17 \\
\hline T2 & 0.207 & 0.046 & 10 \\
\hline T3 & 0.306 & 0.068 & 4 \\
\hline T4 & 0.144 & 0.032 & 16 \\
\hline T5 & 0.207 & 0.046 & 10 \\
\hline
\end{tabular}

Table 4. Classification of PFSC Factors Performance

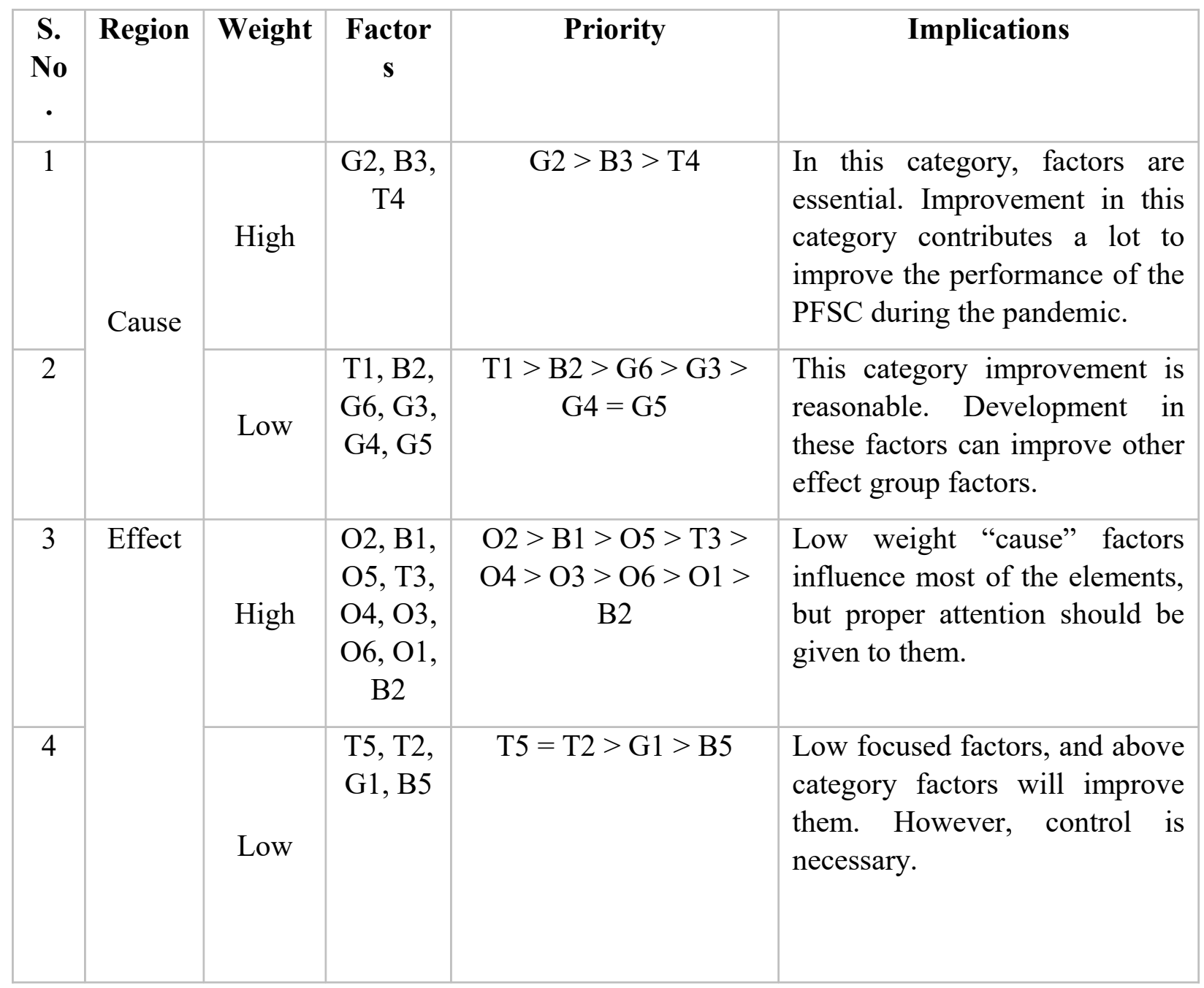




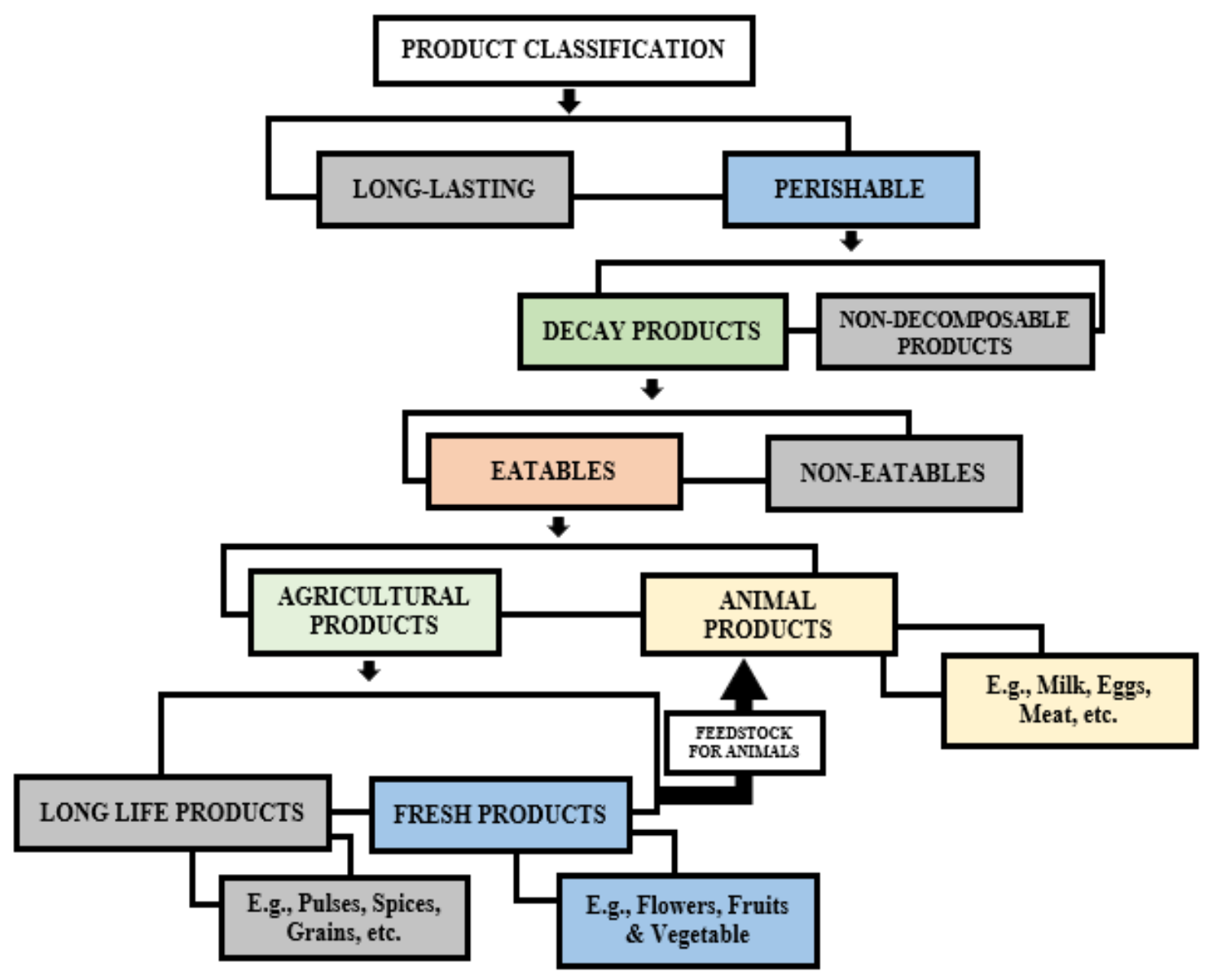

Figure I. Product Differentiation for Perishable Food Sector

Figure II Food Products Exported from the Different States in India and COVID-19 Cases 


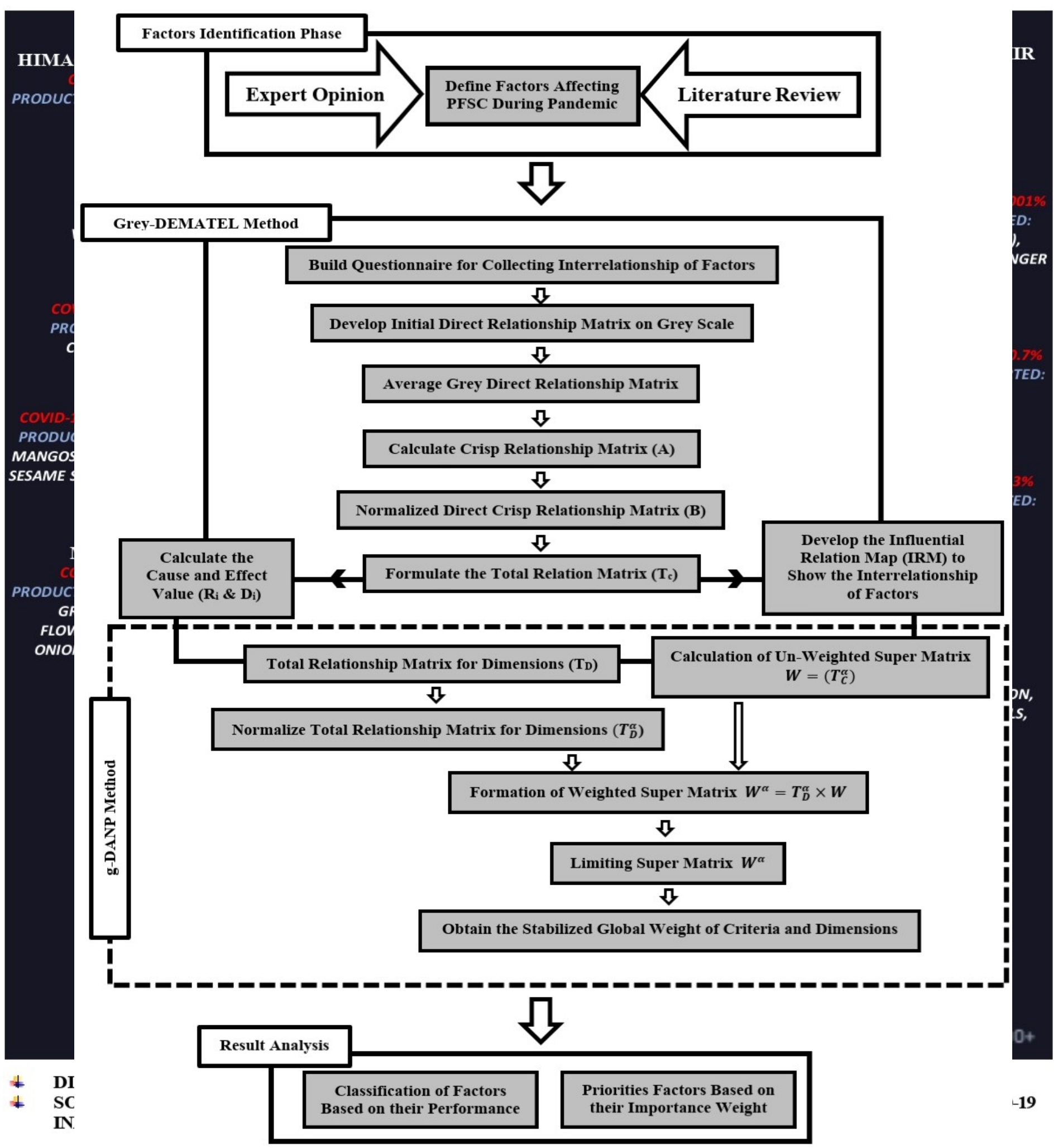

Figure III Flow of Study 


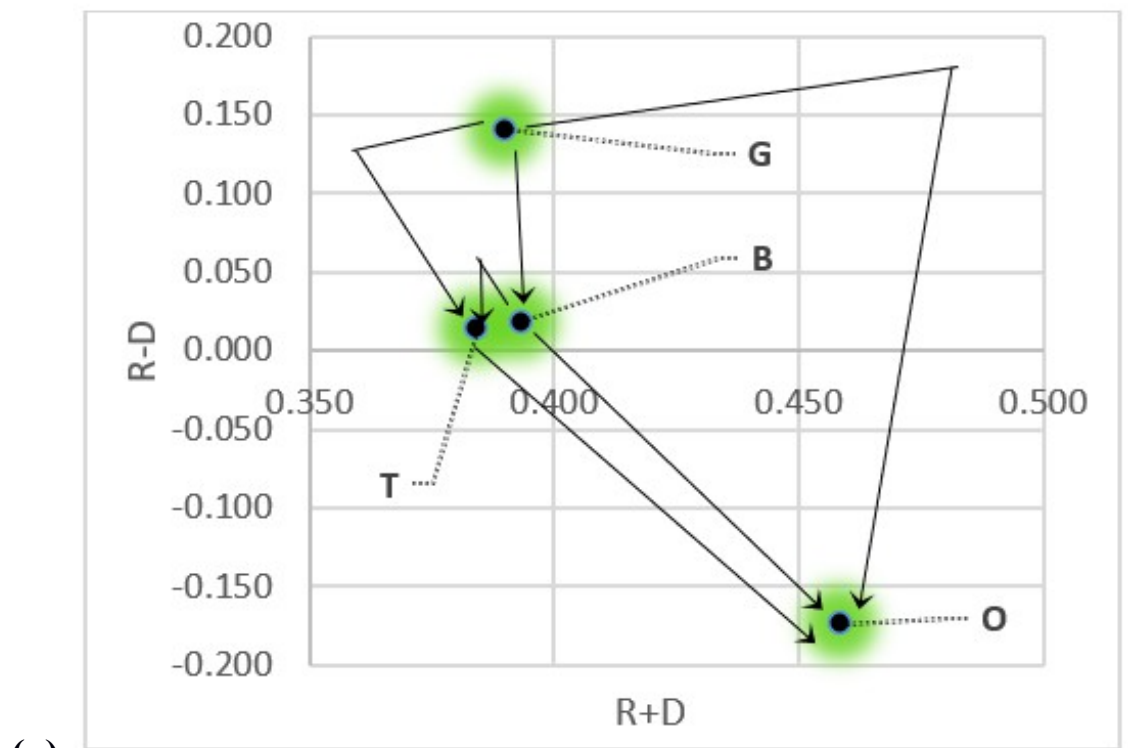

(a)

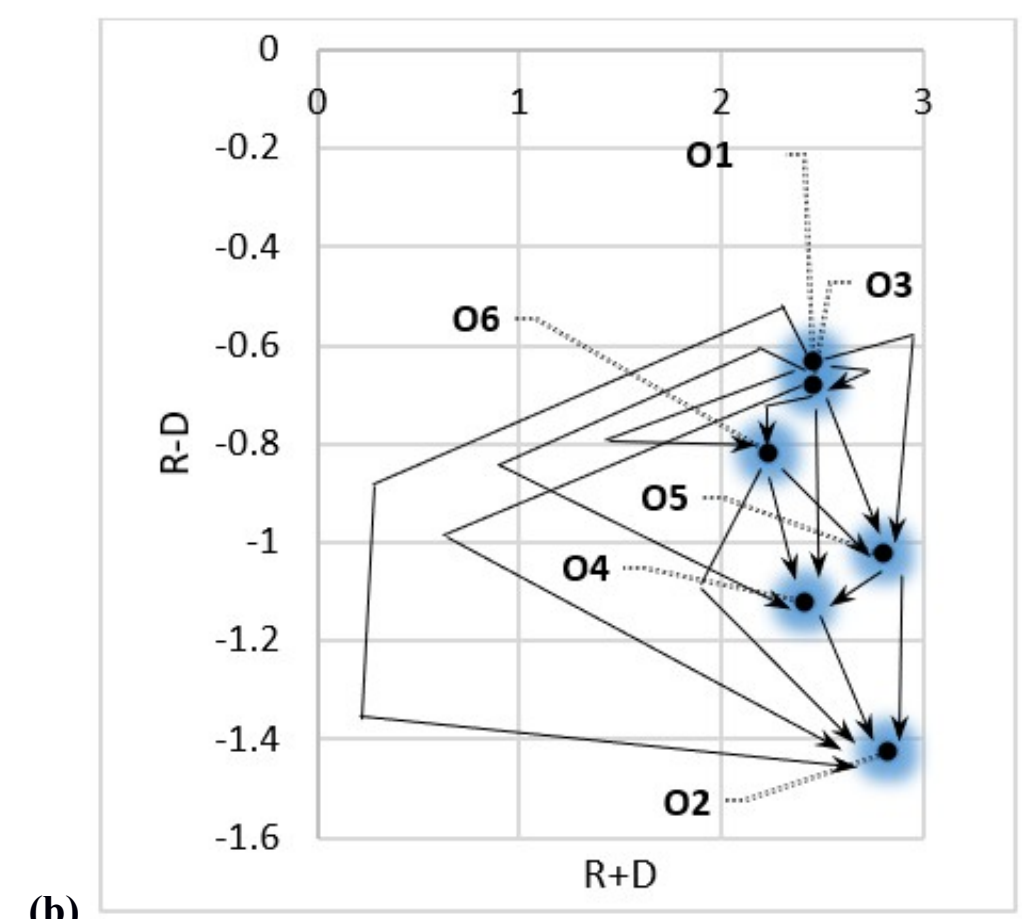

(b)

Figure IV (Influential network relations map (INRM) (a) Dimensions relationship (b) Operational factors relationships, (c) Behavioural factors relationships, (d) Government policy $\&$ regulations factors relationships, (e) Technological \& infrastructural factors relationship) 


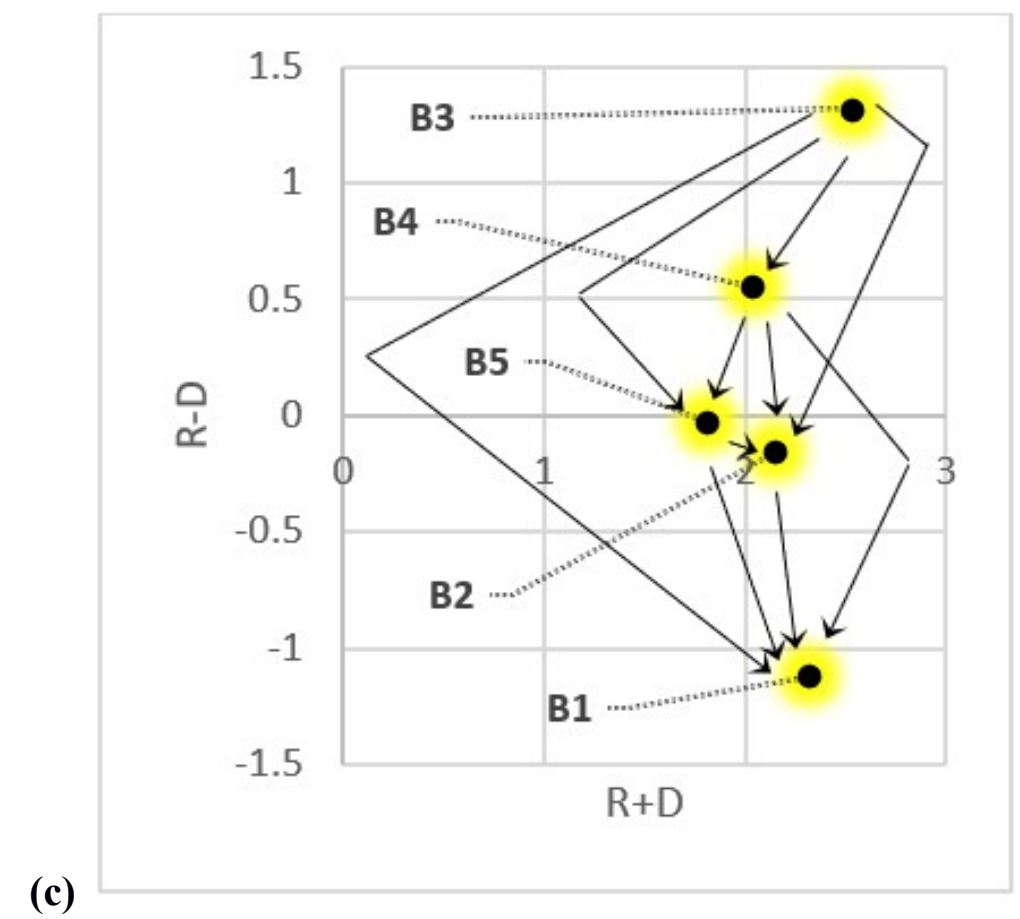

(c)

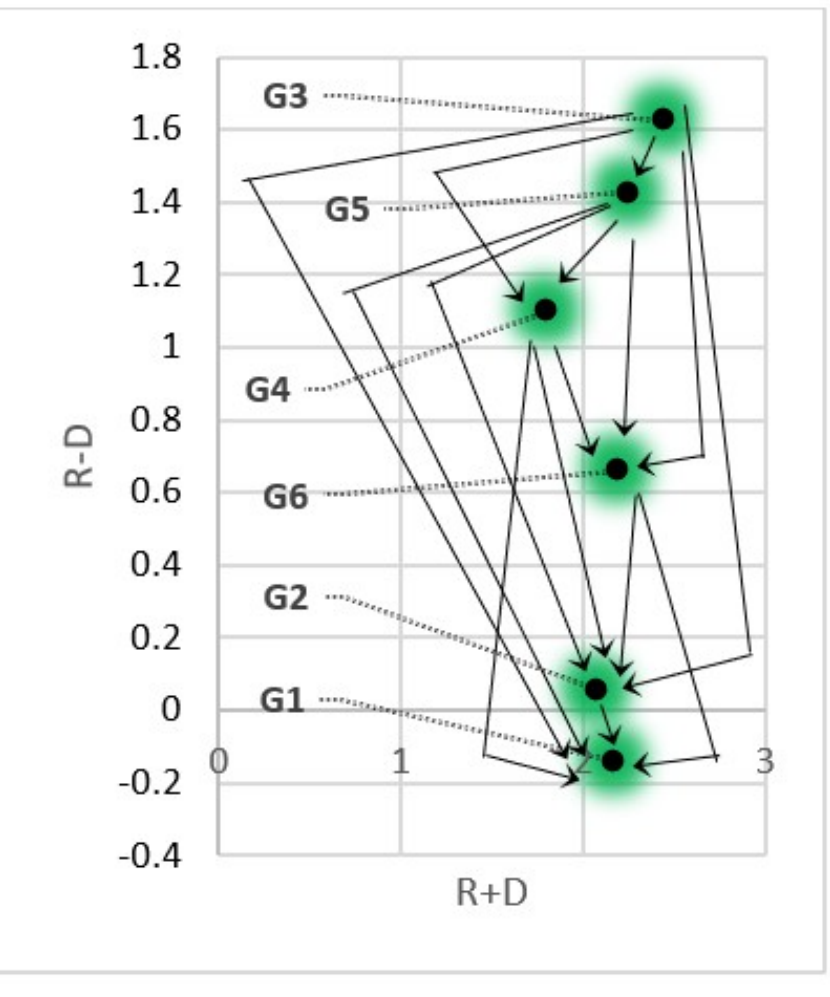




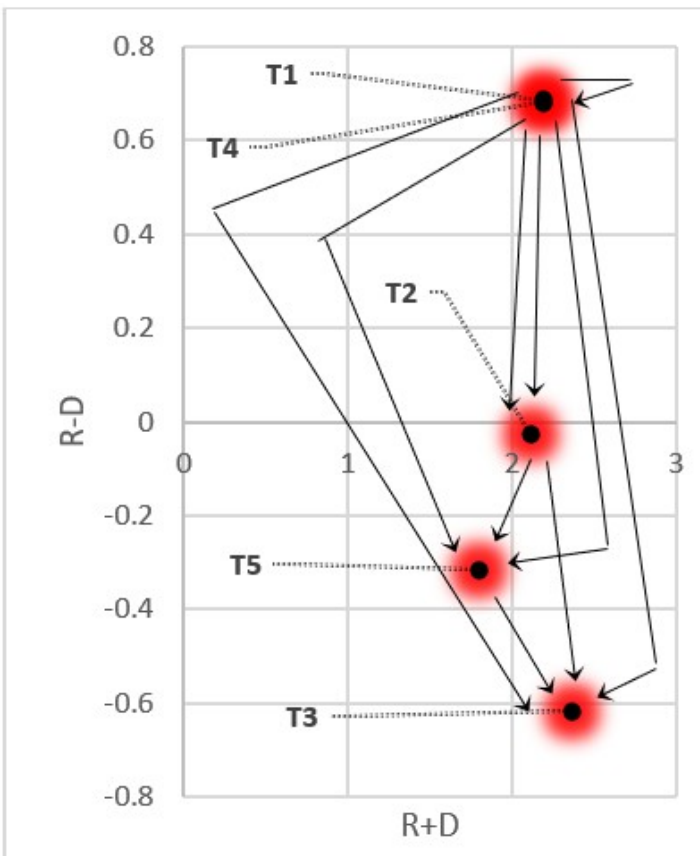

(e) 